\title{
Fundamental limits on inferring epidemic resurgence in real time using effective reproduction numbers
}

\author{
Kris V. Parag ${ }^{1, *}$ and Christl A. Donnelly ${ }^{1,2}$ \\ ${ }^{1} \mathrm{MRC}$ Centre for Global Infectious Disease Analysis, Imperial College London, London, UK. \\ ${ }^{2}$ Department of Statistics, University of Oxford, Oxford, UK. \\ *For correspondence: k.parag@imperial.ac.uk.
}

\begin{abstract}
We find that epidemic resurgence, defined as an upswing in the effective reproduction number $(R)$ of the contagion from subcritical to supercritical values, is fundamentally difficult to detect in real time. Inherent latencies in pathogen transmission, coupled with smaller and intrinsically noisier case incidence across periods of subcritical spread, mean that resurgence cannot be reliably detected without significant delays of the order of the generation time of the disease, even when case reporting is perfect. This belies epidemic suppression (where $R$ falls from supercritical to subcritical values), which may be ascertained 5-10 times more rapidly due to the naturally larger incidence at which control actions are applied. We prove that these innate limits on detecting resurgence only worsen when spatial or demographic heterogeneities are incorporated. Consequently, we argue that resurgence is more effectively handled proactively, at the expense of false alarms. Responses to recrudescent infections or emerging variants of concern will more likely be timely if informed by improved syndromic surveillance systems than by optimised mathematical models of epidemic spread.
\end{abstract}

Keywords: reproduction numbers; infectious diseases; resurgence; real-time limits; models.

\section{Introduction}

Real-time estimates of the transmissibility of an infectious disease [1,2] are crucial for informed outbreak responses. Timely detection of salient changes in the effective reproduction number $(R)$ of the disease of interest, which measures the average number of secondary cases likely caused by a typical primary case, can provide important evidence for policymaking and public communication [3,4], as well as improve forecasts of disease burden [5] (e.g., hospitalisations and deaths). Two critical changes of interest are resurgence and control. Resurgence, which we define as an increase from subcritical $(R \leq 1)$ to supercritical $(R>1)$ transmissibility, can warn of imminent waves of infections, signify the emergence of pathogenic variants of concern and signal important shifts in the behavioural patterns of population [6,7]. Alternatively, control (or suppression) describes a switch from supercritical to subcritical spread and can indicate 

medRxiv preprint doi: https://doi.org/10.1101/2021.09.08.21263270; this version posted November $8,2021$. The copyright holder for this
preprint (which was not certified by peer review) is the author/funder, who has granted medRxiv a license to display the preprint in It is made available under a CC-BY-NC-ND 4.0 International license .

the effectiveness of interventions and the impact of depleting susceptibility (including that due to vaccine-induced immunity) $[8,9]$.

Identifying these transmissibility changes in real time, however, is an enduring challenge for statistical modelling and surveillance planning. Inferring a transition in $R$ from stochastic time series of incident cases necessitates assumptions about the differences among meaningful variations (signal) and random fluctuations (noise) [10-12]. Modern approaches to epidemic modelling and monitoring aim to maximise this signal-to-noise ratio either by enhancing noise filtering and bias correction methods [13-15], or by amplifying signal fidelity through improving surveillance quality and diversity [16-18]. While both approaches have substantially advanced the field, there have been few attempts to explore what, if any, fundamental limits exist on the timely detection of these changes. Such limits can provide key benchmarks for assessing the effectiveness of modelling or data collection and deepen our understanding of what can and cannot be achieved by real-time outbreak response programmes, ensuring that model outputs are not overinterpreted and redirecting surveillance resources more efficiently [19-21].

While studies are examining intrinsic bounds on epidemic monitoring and forecasting [22-25], works on transmissibility have mostly probed how extrinsic surveillance biases might cause $R$ misestimation [14,26-28]. Here we address these gaps in the literature by characterising and exposing fundamental limits to detecting resurgence and control, from a perfectly ascertained incidence time series, using effective reproduction numbers. This presents vital insights into the best real-time performance possible and blueprints for how outbreak preparedness might be improved. We analyse a predominant, flexible real-time epidemic model [1,2] and discover stark asymmetries in our intrinsic ability to detect resurgence and control, emerging from the noisier, low-incidence data underlying possible resurgence events. While epidemic control or suppression change-points are inferred robustly and rapidly, the data bottleneck caused by subcritical spread forces inherent delays (potentially 5-10 times that for control and on the order of the mean disease generation time) that inhibit real-time resurgence estimation.

We show that these innate constraints on resurgence detection worsen with smaller epidemic size, steepness of the upswing in $R$ and spatial or demographic heterogeneities. Given these limitations to timely outbreak analysis, which exist despite perfect case reporting and the use of optimal Bayesian detection algorithms [15,29], we argue that methodological improvements to existing models for analysing epidemic curves (e.g., cases, hospitalisations or deaths) are less important than enhancing syndromic surveillance systems [30,31]. Such systems, which fuse multiple data sources (including novel ones e.g., wastewater [32]) to triangulate possible resurgences might minimize some of these fundamental bottlenecks. We conclude that early 
medRxiv preprint doi: https://doi.org/10.1101/2021.09.08.21263270; this version posted November 8,2021 . The copyright holder for this preprint (which was not certified by peer review) is the author/funder, who has granted medRxiv a license to display the preprint in It is made available under a CC-BY-NC-ND 4.0 International license.

responses to suspected resurging epidemics, at the expense of false alarms, might be justified in many settings, both from our analysis here and the consensus that lags in implementing interventions can translate into severely elevated epidemic burden [33-36]. Using both theory and simulation, we explore and elucidate these conclusions in the next section.

\section{Results}

\section{Epidemic resurgence is statistically more difficult to infer than control}

We first provide intuition for why resurgence and control might present asymmetric difficulties when inferring transmissibility in real time. We consider an epidemic modelled via a renewal branching process [37] over times (usually in days) $1 \leq s \leq t$. Such models have been widely applied to infer the transmissibility of numerous diseases including Ebola virus, COVID-19 and pandemic influenza. Renewal models postulate that the incidence of new cases at some time $s$, denoted $I_{S}$, depends on the effective reproduction number, $R_{S}$, and the past incidence, $I_{1}^{S-1}$ as in Eq. (1) [2]. Here $I_{a}^{b}$ means the set $\left\{I_{a}, I_{a+1}, \ldots, I_{b}\right\}$ and $\equiv$ indicates equality in distribution.

$$
\mathrm{P}\left(I_{s} \mid R_{S}, I_{1}^{S-1}\right) \equiv \operatorname{Pois}\left(R_{s} \Lambda_{s}\right), \quad \Lambda_{s}=\sum_{u=1}^{s-1} w_{u} I_{s-u}
$$

In Eq. (1), Pois represents Poisson noise and $\Lambda_{S}$ is the total infectiousness, which summarises the weighted influence of past infections. The set of weights $w_{u}$ for all $u$ define the generation time distribution of the infectious disease with $\sum_{u=1}^{\infty} w_{u}=1$ [38]. Applying Bayesian inference techniques (see Methods in the Supplement for derivations) [2,39] under the assumption that transmissibility is constant over a past window of size $m$ days, $\tau(s)=\{s, s-1, \ldots, s-m+1\}$, we obtain the gamma (Gam) posterior distribution $\mathrm{P}\left(R_{s} \mid I_{1}^{S}\right) \approx \mathrm{P}\left(R_{s} \mid I_{s-m+1}^{s}\right) \equiv \operatorname{Gam}(a+$ $\left.i_{\tau(s)},\left(c+\lambda_{\tau(s)}\right)^{-1}\right)$, with sums of $i_{\tau(s)}=\sum_{u \in \tau(s)} I_{u}$ and $\lambda_{\tau(s)}=\sum_{u \in \tau(s)} \Lambda_{u}$.

Here $(a, c)$ are prior distribution $\left(\mathrm{P}\left(R_{S}\right)\right)$ parameters, which are set so the prior mean of $R_{S}$ is above 1 but uninformative. This maximises sensitivity to resurgence since the model, in the absence of data, favours $\mathrm{E}\left[R_{S}\right]>1$. The approximations above and later emerge from the window assumption and underpin popular real-time $R$-inference methods $[2,40]$. Using this renewal formulation, we define the relative change in the epidemic size as $\Delta \lambda_{\tau(s)}=\frac{i_{\tau(s)}-\lambda_{\tau(s)}}{\lambda_{\tau(s)}}$. This measures the perturbation to the past incidence (summarised by $\lambda_{\tau(s)}$ ) that the most 
medRxiv preprint doi: https://doi.org/10.1101/2021.09.08.21263270; this version posted November 8, 2021. The copyright holder for this preprint (which was not certified by peer review) is the author/funder, who has granted medRxiv a license to display the preprint in It is made available under a CC-BY-NC-ND 4.0 International license .

recently observed incidence, $i_{\tau(s)}$, causes over $\tau(s)$. Normalising by $\lambda_{\tau(s)}$ is sensible as the posterior mean estimate of $R_{S}$ is roughly $\frac{i_{\tau(s)}}{\lambda_{\tau(s)}}$, so $\Delta \lambda_{\tau(s)}$ approximates $R_{s}-1$.

This posterior distribution only uses data up until time $s$ and defines our real-time estimate of $R$ at that time. We can analyse its properties (and related likelihood function $\mathrm{P}\left(I_{s-m+1}^{S} \mid R_{S}\right)$ ) to obtain the Fisher information (FI) on the left side of Eq. (2). We derive this expression in the Methods of the Supplement. This FI captures how informative $I_{1}^{S}$ is (in this case approximated by $I_{S-m+1}^{S}$ ) for inferring $R_{S}$, with its inverse defining the smallest asymptotic variance of any $R_{S}$ estimate [10,41]. Larger FI implies better statistical precision.

$$
\mathrm{FI}\left[R_{s}\right]=\frac{\lambda_{\tau(s)}}{R_{s}}, \quad \mathrm{P}\left(R_{s}>1 \mid I_{1}^{S}\right)=\sum_{j=0}^{a-1+i_{\tau(s)}} \frac{\left(c+\lambda_{\tau(s)}\right)^{j}}{j !} e^{-\left(c+\lambda_{\tau(s)}\right)}
$$

As resurgence will likely follow low-incidence periods, we might expect $\lambda_{\tau(s)}$ to be small, while $R_{S}$ rises. This effect will reduce the FI in Eq. (2), making these changes harder to detect. In contrast, the impact of interventions will be easier to infer since these are often applied when cases are larger and reduce $R_{S}$. This observation applies for any $\tau(s)$ and is fundamental as it delimits the best estimator performance under our renewal model (Cramer-Rao bound) [42].

We expand on this intuition, using the $R$ posterior distribution to derive (see Methods) the realtime resurgence probability $\mathrm{P}\left(R_{S}>1 \mid I_{1}^{S}\right) \approx \int_{1}^{\infty} \mathrm{P}\left(R_{S} \mid I_{S-m+1}^{S}\right) d R_{S}$, as on the right side of Eq. (2). We plot its implications in Figure 1, corroborating our intuition. In panel A we find that larger past epidemic sizes $\left(\lambda_{\tau(s)}\right)$ improve our ability to detect shifts in transmissibility from fluctuations in incidence (the posterior distributions for $R_{S}$ overlap less). Panel B bolsters this idea, showing that when $\lambda_{\tau(s)}$ is smaller (as is likely before resurgence) we need to observe larger relative epidemic size changes $\left(\Delta \lambda_{\tau(s)}\right)$ for some increase in $\mathrm{P}\left(R_{S}>1 \mid I_{1}^{S}\right)$ than for an equivalent decrease when aiming to detect control (where $\lambda_{\tau(s)}$ would generally be larger). This detection asymmetry holds for arbitrary window size and indicates that data bottlenecks translate into real-time detection delays. We assess the magnitude of these delays next. 

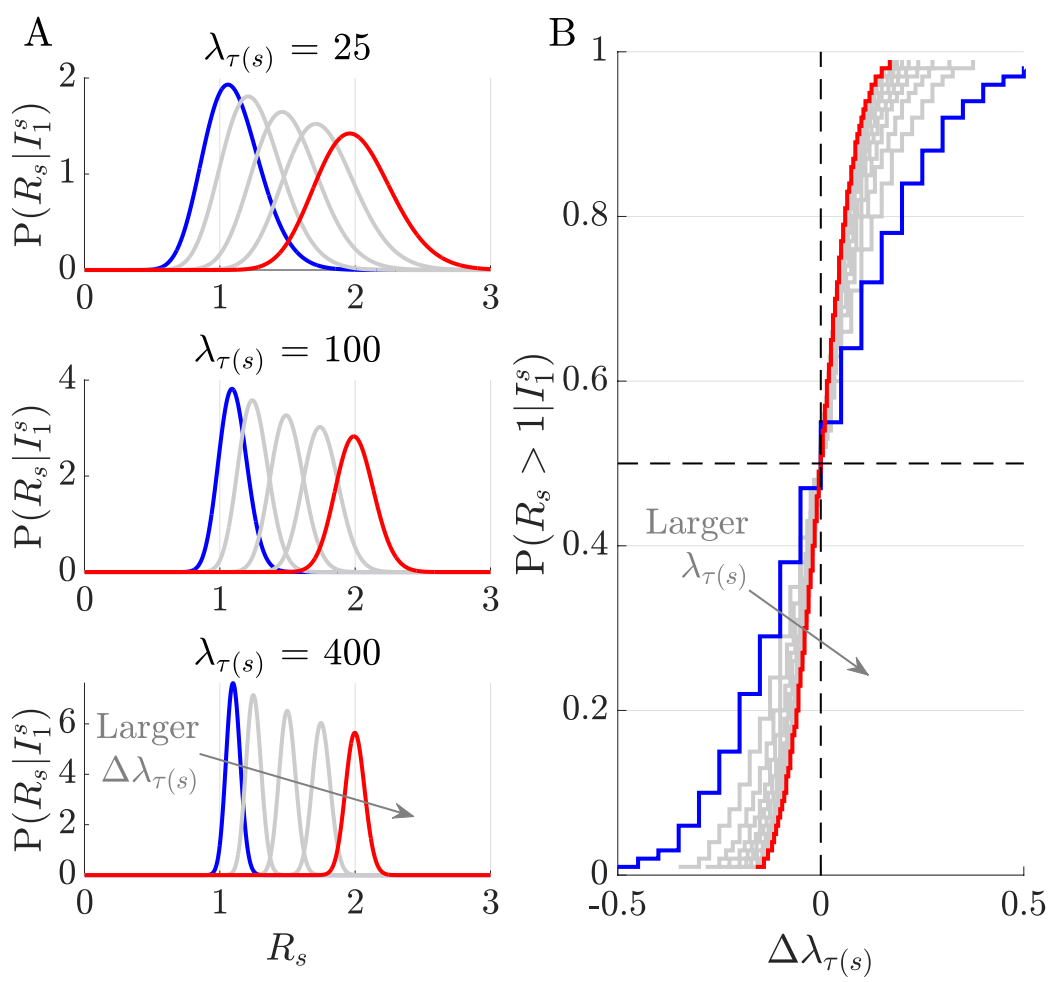

Figure 1: Relative sensitivity to perturbations in incidence. Panel A plots posterior realtime distributions for the effective reproduction numbers, $R_{S}$, at different relative incidence perturbations, $\Delta \lambda_{\tau(s)}=\frac{i_{\tau(s)}-\lambda_{\tau(s)}}{\lambda_{\tau(s)}}$, (increasing from blue to red). The degree of separation and hence our ability to uncover meaningful incidence fluctuations from noise, improves with the current epidemic size, $\lambda_{\tau(s)}$. Panel B shows how this sensitivity modulates our capacity to infer resurgence $\left(\mathrm{P}\left(R_{S}>1 \mid I_{1}^{S}\right)\right)$ and control $\left(\mathrm{P}\left(R_{S} \leq 1 \mid I_{1}^{S}\right)=1-\mathrm{P}\left(R_{S}>1 \mid I_{1}^{S}\right)\right)$. If epidemic size is smaller, larger relative incidence changes are needed to detect changes in $R_{S}$ (curves have gentler gradient). Resurgence (likely closer to the blue line, top right quadrant) is appreciably and innately harder to detect than control (likely closer to the red line, bottom left quadrant).

\section{Fundamental delays on detecting resurgence but not control}

The intrinsic asymmetry in sensitivity to upward versus downward shifts in $R$ (see Figure 1) implies that it is not equally simple to infer resurgence and control from incident cases. We investigate ramifications of this observation by comparing our real-time $R_{S}$-estimates to ones exploiting all the future incidence information available. We no longer consider window-based approximations (which we only use to extract analytic insights) but instead apply formal realtime Bayesian inference and detection algorithms [29]. We investigate two foundational posterior distributions, the filtered, $p_{s}$, and smoothed, $q_{s}$, distributions, defined as in Eq. (3). 

medRxiv preprint doi: https://doi.org/10.1101/2021.09.08.21263270; this version posted November $8,2021$. The copyright holder for this
preprint (which was not certified by peer review) is the author/funder, who has granted medRxiv a license to display the preprint in It is made available under a CC-BY-NC-ND 4.0 International license .

$$
p_{s}=\mathrm{P}\left(R_{s} \mid I_{1}^{s}\right), \quad q_{s}=\mathrm{P}\left(R_{s} \mid I_{1}^{t}\right), \quad \mathrm{D}\left(p_{s} \mid q_{s}\right)=\int_{0}^{\infty} p_{s} \log \frac{p_{s}}{q_{s}} d R_{s}
$$

Here $p_{s}$ considers all information until time $s$ and captures changes in $R_{S}$ from $I_{1}^{S}$ in real time. Estimates of $R_{S}$ using this posterior distribution minimise the mean squared error (MSE) given $I_{1}^{S}$. In contrast, $q_{s}$ extracts all the information from the full incidence curve $I_{1}^{t}$, providing the minimum MSE $R_{S}$-estimate given $I_{1}^{t}$ [29]. This smoother MSE is never larger and may be substantially smaller than the filtered MSE due to its use of additional information (i.e., $I_{S+1}^{t}$ ) $[29,43]$. The differential between $p_{s}$ and $q_{s}$, summarised via the Kullback-Liebler divergence, $\mathrm{D}\left(p_{s} \mid q_{s}\right)$, measures the value of this additional 'future' information.

Bayesian filtering and smoothing are central formalisms across engineering, where real-time inference and detection problems are common [29,44]. We compute formulae from Eq. (3) via the EpiFilter package (see Supplement and [15,28]), which applies optimal forward-backward algorithms, improves on the window-based approach of the last section and maximises the signal-to-noise ratio in $R$-estimation. We further obtain filtered and smoothed probabilities of resurgence as $\mathrm{P}\left(R_{S}>1 \mid I_{1}^{S}\right)=\int_{1}^{\infty} p_{s} d R_{S}$ and $\mathrm{P}\left(R_{S}>1 \mid I_{1}^{t}\right)=\int_{1}^{\infty} q_{s} d R_{S}$. The probability that the epidemic is controlled (i.e., $R \leq 1$ ) is the complement of these expressions. Our main results, which average the above quantities over many simulated Ebola virus and COVID-19 epidemics, are given in Figure $\mathbf{2}$ and Supplement Figure $\mathbf{A}$, respectively (accompanying simulated incidence curves are provided in Supplement Figures B-C). We uncover striking differences in the intrinsic ability to infer resurgence versus control in real time.

Upward change-points are significantly harder to detect both in terms of accuracy and timing. Discrepancies between $p_{s}$ - and $q_{s}$-based estimates (the latter benchmark the best realisable performance) are appreciably larger for resurgence than control. While decreases in $R$ can be pinpointed reliably, increases seem fundamentally more difficult to detect. These limits appear to exacerbate with the steepness of the $R$ upswing. We confirm these trends with a detailed simulation study across five infectious diseases in Figure 3. There we alter the steepness, $\theta$, of transmissibility changes and map delays in detecting resurgence and control as a function of the difference in the first time that $p_{s}$ - and $q_{s}$-based probabilities cross $0.5\left(\Delta t_{50}\right)$ and 0.95 $\left(\Delta t_{95}\right)$, normalised by the mean generation time of the disease. We find that lags in detecting resurgence can be at least 5-10 times longer than for detecting control and are of the order of the average intrinsic generation time of the disease. 
A
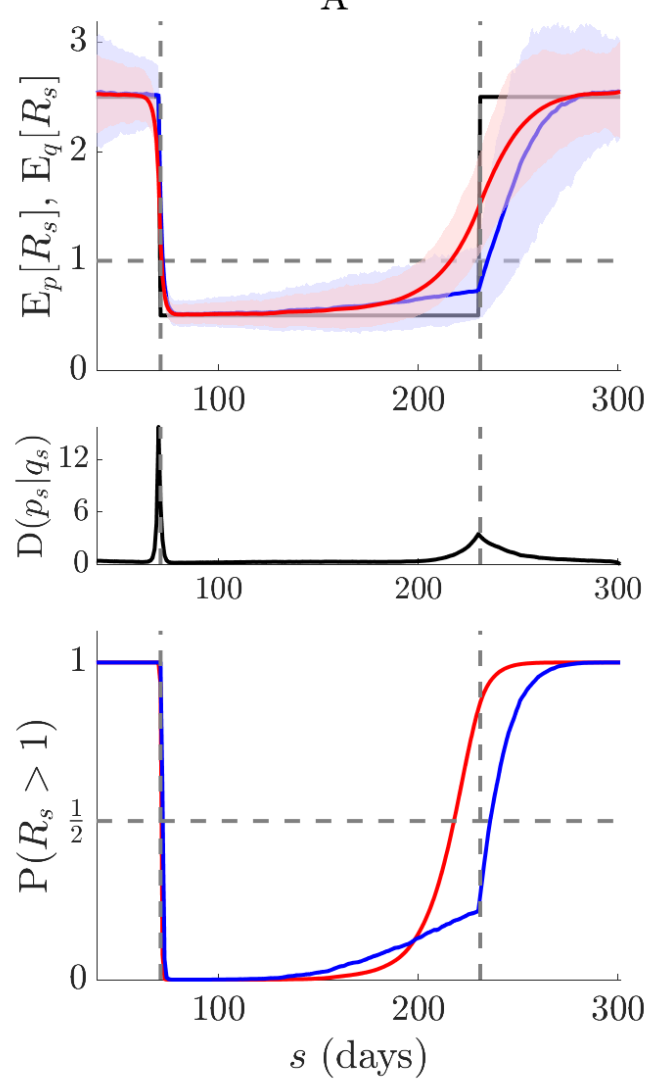

Ebola virus dynamics
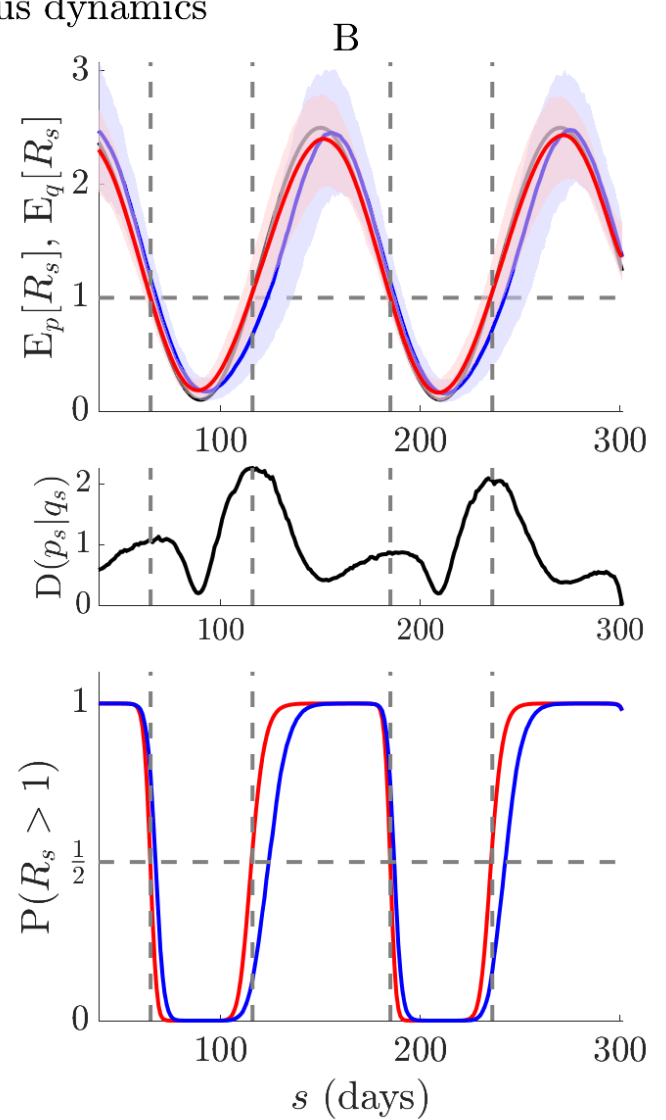

Figure 2: Resurgence and control dynamics of Ebola virus. Using renewal models with the generation time from [45], we simulate 1000 realisations of Ebola virus epidemics ( $t=$ 300 ) with step (A panels) and seasonally (B panels) changing transmissibility. Top panels plot mean estimates from the filtered $\left(\mathrm{E}_{p}\left[R_{S}\right]\right.$, blue) and smoothed $\left(\mathrm{E}_{q}\left[R_{S}\right]\right.$, red) distributions from every realisation (computed using EpiFilter [15]). Middle panels average the Kullback-Liebler divergences from those simulations and bottom panels present overall filtered $\left(\mathrm{P}\left(R_{S}>1 \mid I_{1}^{S}\right)\right.$, blue), and smoothed $\left(\mathrm{P}\left(R_{s}>1 \mid I_{1}^{t}\right)\right.$, red) resurgence probabilities. We find fundamental and striking delays in detecting resurgence, often an order of magnitude longer than those for detecting control or suppression in transmission (see lags between red and blue curves). Note that the initial rise in $\mathrm{P}\left(R_{S}>1 \mid I_{1}^{S}\right)$ of panel $\mathrm{A}$, which precedes the transition in $R_{S}$, is due to the influence of the prior distribution (which has mean above 1) in a period with very few cases. We present the incidence curves for the simulations here in Figure $\mathbf{C}$ of the Supplement. 

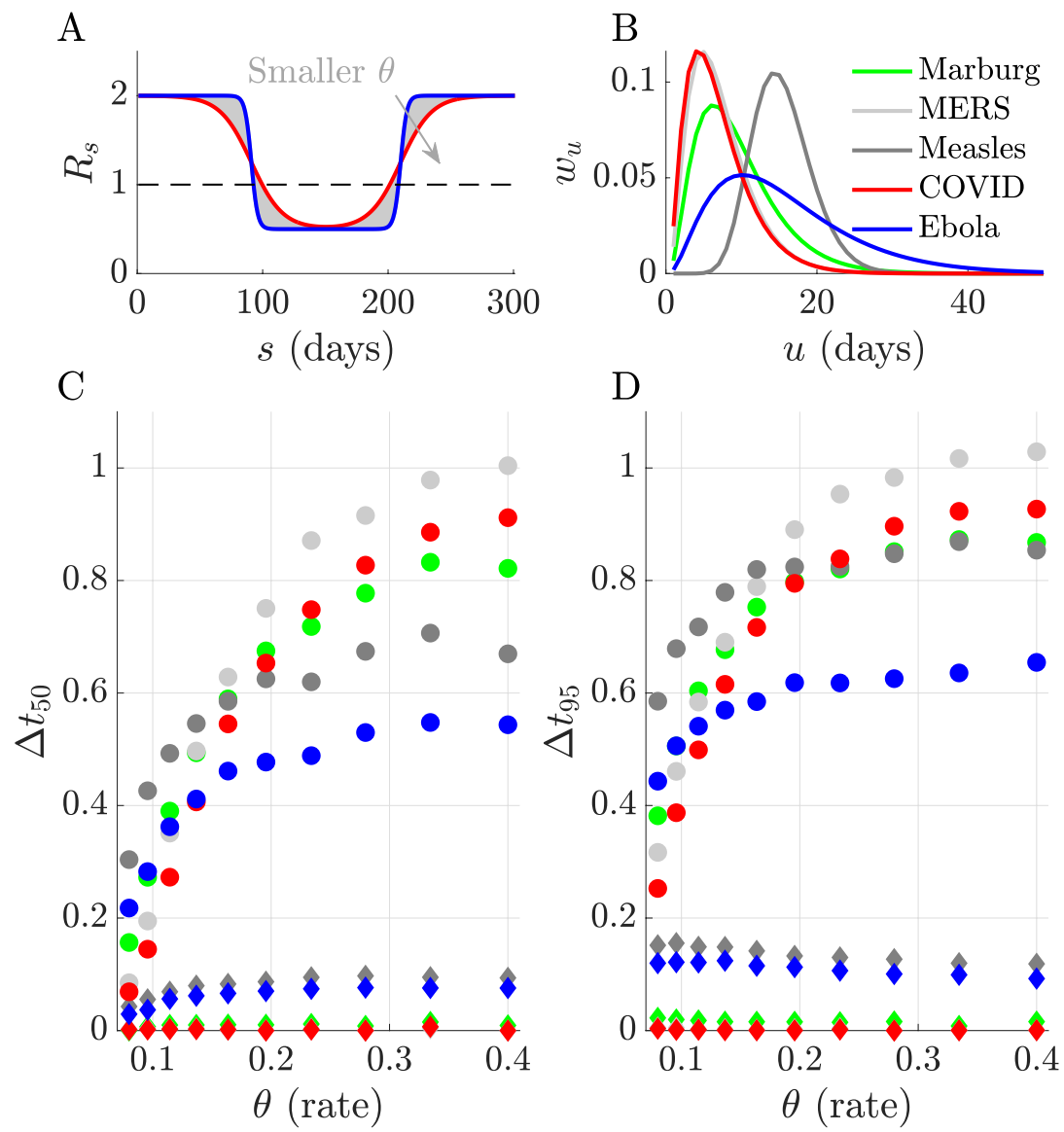

Figure 3: Delays in detecting upward and downward changes in $R$. We characterise the discrepancies between detecting resurgence and control against the steepness or rate, $\theta$, of changes in transmissibility $\left(R_{S}\right)$, which we model with logistic functions (panel A). We compare differences in the probability of detecting resurgence $\left(\mathrm{P}\left(R_{S}>1\right)\right)$ or control $\left(\mathrm{P}\left(R_{S} \leq 1\right)\right.$ under filtered and smoothed estimates (see main text) first crossing thresholds of $0.5\left(\Delta t_{50}\right)$ and 0.95 $\left(\Delta t_{95}\right)$ for five infectious diseases (panel B plots their assumed generation time distributions from $[2,45,46])$. We simulate 1000 epidemics from each disease using renewal models and estimate $R_{S}$ with EpiFilter [15]. Panels $\mathrm{C}$ and $\mathrm{D}$ (colours match panel $\mathrm{B}, \Delta t$ is normalised by the mean generation times of the diseases) show that delays in detecting resurgence (dots) are at least 5-10 times longer than for indicating control (diamonds). Our ability to infer even symmetrical transmissibility changes is fundamentally asymmetric.

\section{Fundamental delays worsen with spatial or demographic heterogeneities}

In previous sections we demonstrated that sensitivity to changes in $R$ is asymmetric, and that intrinsic, restrictive limits exist on detecting resurgence in real time, which do not equally inhibit detecting control. While those conclusions apply generally (e.g., across diseases), they do not 
medRxiv preprint doi: https://doi.org/10.1101/2021.09.08.21263270; this version posted November 8,2021 . The copyright holder for this preprint (which was not certified by peer review) is the author/funder, who has granted medRxiv a license to display the preprint in It is made available under a CC-BY-NC-ND 4.0 International license .

consider the influence of spatial or demographic heterogeneity. We examine this complexity through a simple but realistic generalisation of the renewal model. Often $R$-estimates can be computed at small scales (e.g., at the municipality level) via local incidence or more coarsely (e.g., countrywide), using aggregated case counts $[3,13]$. We can relate these differing scales with the weighted mean in Eq. (4), where the overall (coarse) $R$ at time $s, \bar{R}_{S}$, is a convex sum of finer-scale $R$ contributions from each group $\left(R_{S}[j]\right.$ for the $j^{\text {th }}$ of $p$ groups) weighted by the epidemic size of that group (as in Eq. (2) we use windows $\tau(s)$ for analytic insight).

$$
\bar{R}_{s}=\sum_{j=1}^{p} R_{s}[j] \alpha_{j}, \quad \alpha_{j}=\frac{\lambda_{\tau(s)}[j]}{\sum_{k=1}^{p} \lambda_{\tau(s)}[k]}
$$

Our choice of groupings is arbitrary and can equally model demographic heterogeneities (e.g., age-specific transmission), where we want to understand how dynamics within the subgroups influence overall spread [7]. Our aim is to ascertain how grouping, which often occurs naturally due to data constraints or a need to succinctly describe the infectious dynamics over a country to aid policymaking or public communication [47], affects resurgence detection. Eq. (4) implies that $\bar{R}_{S}-1=\sum_{j=1}^{p}\left(R_{S}[j]-1\right) \alpha_{j}$. Since resurgence will likely first occur within some specific (maybe high risk) group and then propagate to other groups [7], this expression suggests that an initial signal (e.g., if some $R_{S}[j]>1$ ) could be masked by non-resurging groups (which are, from this perspective, contributing background noise).

As the epidemic size in a resurging group will likely be smaller than those of groups with past epidemics that are now being stabilised or controlled, this exacerbates the sensitivity bounds explored earlier via Eq. (2). We can verify this further loss of sensitivity by examining how the overall posterior distribution depends on those of the component groups as follows, with $\circledast$ as a repeated convolution operation and $\Omega_{j}$ as the posterior distribution for the $j^{\text {th }}$ group.

$$
R_{s}[j] \sim \Omega_{j}\left(i_{\tau(s)}[j], \quad \lambda_{\tau(s)}[j]\right), \quad \bar{R}_{s} \sim \circledast_{j=1}^{p} \alpha_{j} \Omega_{j} .
$$

While Eq. (5) holds generally, we assume gamma posterior distributions, leading to statistics analogous to Eq. (2). We plot these sensitivity results at $p=2$ and 3 in Figure 4 , where group 1 features resurgence and other groups either contain stable or falling incidence. We find that as $p$ grows (and additional distributions convolve to generate $\bar{R}_{S}$ ) we lose sensitivity (posterior distributions overlap more for a given relative change in incidence $\left(\Delta \lambda_{\tau(s)}[1]=\frac{i_{\tau(s)}[1]-\lambda_{\tau(s)}[1]}{\lambda_{\tau(s)}[1]}\right)$. Reductions in either the weight $\left(\alpha_{1}\right)$, epidemic size $\left(\lambda_{\tau(s)}[1]\right)$ or other $R_{S}[j \neq 1]$, further desensitise the resurgence signals i.e., decrease the gradient of detection probability curves. 
medRxiv preprint doi: https://doi.org/10.1101/2021.09.08.21263270; this version posted November 8, 2021. The copyright holder for this preprint (which was not certified by peer review) is the author/funder, who has granted medRxiv a license to display the preprint in It is made available under a CC-BY-NC-ND 4.0 International license .

This is summarised by noting that if $R_{S}[1]=\max _{j} R_{s}[j]$, then the sensitivity from Eq. (2) is only matched when the resurging group dominates $\left(\alpha_{1} \approx 1\right)$ or if other groups have analogous $R$ i.e., $R_{S}[1] \approx R_{S}[j]$. Delays in detecting resurgence can therefore be severe. Heterogeneity on its own, however, does not force asymmetry between detecting control and resurgence.
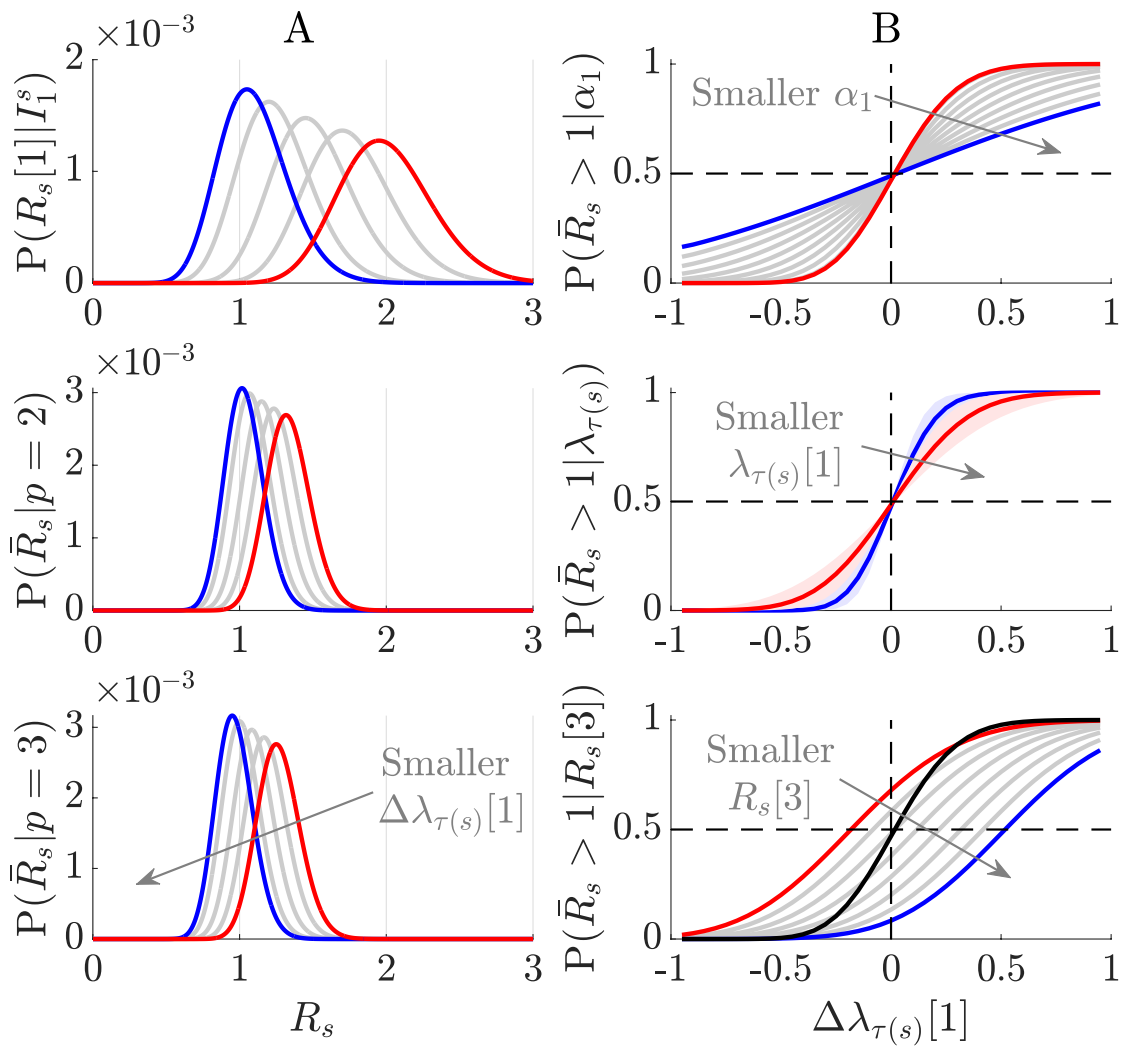

Figure 4: Influence of heterogeneities in transmission. We investigate how differences in transmissibility among groups (e.g., due to demographic or spatial factors) fundamentally limit the ability to detect resurgence from a specific group (in this example group 1). Panel A shows that the grouped posterior distribution becomes less sensitive to relative changes in group 1 incidence, $\Delta \lambda_{\tau(s)}[1]=\frac{i_{\mathcal{\tau}(s)}[1]-\lambda_{\tau(s)}[1]}{\lambda_{\tau(s)}[1]}$ (increasing from blue to red). Posterior distributions over $\bar{R}_{S}$ are more overlapped (and tighter in variance) as $p$ increases, for fixed $R_{S}[1]$ (top). Panel B plots how overall resurgence detection probability $\mathrm{P}\left(\bar{R}_{S}>1\right)$ depends on the weight $\left(\alpha_{1}\right.$, top, 0.05-1) and epidemic size $\left(\lambda_{\tau(s)}[1]\right.$, middle, 20-80, $\left.p=2\right)$ as well as changes in $R_{S}[3]$ (bottom, $0.5-1.2, p=3$ ). Decreases in $\alpha_{1}$ (red to blue) or $\lambda_{\tau(s)}$ [1] mean other groups mask the resurging dynamics in group 1 , reducing sensitivity (curves become less steep). In the latter case the $\mathrm{P}\left(\bar{R}_{S}>1\right)$ (red with solid line at median of $\lambda_{\tau(s)}[1]$ range) is always more 
medRxiv preprint doi: https://doi.org/10.1101/2021.09.08.21263270; this version posted November 8,2021 . The copyright holder for this preprint (which was not certified by peer review) is the author/funder, who has granted medRxiv a license to display the preprint in It is made available under a CC-BY-NC-ND 4.0 International license .

conservative than $\mathrm{P}\left(R_{S}[1]>1\right)$ (blue, solid median line). As $R_{S}[3]$ falls (red to blue) the ability to detect resurgence also lags relative to that from observing group 1 (black).

\section{Discussion}

Probing the performance limits of noisy biological systems has yielded important insights into the real-time estimation and control of parameters in biochemistry and neuroscience [48-50]. Although models from these fields share dynamic similarities with those in epidemiology, there has been relatively little investigation of how real-time estimates of pathogen transmissibility, parametrised by $R$, might be fundamentally limited. This is surprising since $R$ is among key parameters considered in initiatives aiming to better systematise real-time epidemic response [40,51]. Here we explored what limits may exist on our ability to reliably detect or measure the change-points in $R$ that signify resurgence and control. By using a combination of Bayesian sensitivity analyses and minimum MSE filtering and smoothing algorithms, we discovered striking asymmetries in innate detection sensitivities. We found that, arguably, the most crucial transitions in epidemic transmissibility are the most inherently difficult to detect.

Specifically, resurgence, signified by an increase in $R$ from below to above 1 , can possibly be detected only 5-10 times later than an equivalent decrease in $R$ that indicated control (Figure 2, Figure 3 and Supplement Figure A). As this lag can be of the order of the mean generation time of the disease under study, even when case reporting is perfect and optimised detection algorithms are applied, this represents a potentially sharp bottleneck to real-time responses for highly contagious diseases. Intuition for this result came from observing that sensitivity to $R$ change-points will weaken (due to noise masking the signal) with declining epidemic sizes or case incidence, and increasing 'true' $R$, both of which likely occur in resurgent settings due to periods of subcritical spread (Eq. (2) and Figure 1). The converse applies to control, which is usually enforced in larger (and less intrinsically noisy) incidence regimes. Furthermore, we found that these latencies and sensitivity issues would only exacerbate when heterogeneous groupings across geography or demography (Eq. (4), (5) and Figure 4) are considered.

Practical real-time analyses would almost surely involve such groupings or data aggregations $[9,13]$, and be subject to reporting and other latencies (e.g., if notifications, hospitalisations or deaths are used as proxies for incidence), which introduce additive delays on top of those we uncovered [14,52]. Consequently, we argue that while case data may provide robust signals for pinpointing when an epidemic is under control (and possibly disentangling the impact of interventions), they are insufficient, on their own, to sharply resolve resurgence timepoints. This does not invalidate the importance of approaches seeking to better characterise real-time $R$ changes $[1,2,13,28]$, but instead contextualises how such inferences should be interpreted 

medRxiv preprint doi: https://doi.org/10.1101/2021.09.08.21263270; this version posted November $8,2021$. The copyright holder for this
preprint (which was not certified by peer review) is the author/funder, who has granted medRxiv a license to display the preprint in It is made available under a CC-BY-NC-ND 4.0 International license .

when informing policy. Given intrinsic delays in inferring resurgence, which can associate with critical epidemiological changes, such as the emergence of variants of concern or important shifts in population behaviours [6,7], there are grounds for conservative approaches that enact interventions early at the expense of false alarms. This might support, for example the ongoing COVID-19 policies of New Zealand and Australia [53], and adds impetus to recent studies showing how lags in the implementing of interventions can induce drastic costs [33-36].

Moreover, our analysis suggests that enhancing syndromic surveillance systems, which can comprehensively engage diverse data sources $[30,31]$ may be more important than improving models for processing case data. Fusing multiple and sometimes novel data sources, such as wastewater or cross-sectional viral loads [18,32], may present the only truly realistic means of minimizing the innate limits to resurgence detection that we have demonstrated. Approaches aimed at enhancing case-based inference generally correct reporting biases or propose more robust measures of transmissibility, such as time-varying growth rates [14,40,54]. However, as our study highlights limits that persist at the gold standard of perfect case reporting and, further it is known that under such conditions growth rates and $R$ are equally informative [55], these lines of investigation are unlikely to minimise the bottlenecks we have exposed.

There are three main limitations of our results. First, as we only considered renewal model epidemic descriptions, which predominate real-time $R$ studies, our work necessarily neglects the often-complex contact network structures that can mediate infection spread [56]. However, other analyses using somewhat different approaches to ours (e.g., Hawkes processes [57]) show apparently similar sensitivity asymmetries and there is evidence that renewal models may be as accurate as network models for inferring $R$ [58], while being easier to run and fit in real time. Moreover, it is known that renewal models are equivalent to various compartmental models depending on the choice of generation time distribution [59]. Given this flexibility of description and that the asymmetry we discovered is contingent on low-incidence data being noisier and typical of resurgence settings, which is a model agnostic point, we expect that the fundamental limits we have exposed are general and not a renewal model artefact.

Second, while we analysed one common and important definition of resurgence that depends on effective reproduction numbers, other more recent definitions of epidemic re-emergence exist that are linked to complex dynamic characteristics of diseases such as critical slowing down [60]. Our aim was to understand and expose limitations of the most common surveillance data types (incidence) and the most prominent epidemic summary statistics (time-varying or effective reproduction numbers), which are among those informing policy [40], so we did not examine such metrics. Testing to see if these other characteristics also show asymmetry could 
medRxiv preprint doi: https://doi.org/10.1101/2021.09.08.21263270; this version posted November 8, 2021. The copyright holder for this preprint (which was not certified by peer review) is the author/funder, who has granted medRxiv a license to display the preprint in It is made available under a CC-BY-NC-ND 4.0 International license .

be an interesting follow-up study but would require different modelling approaches. Last, we did not include any explicit economic modelling. While this is outside the scope of this work it is important to recognise that resurgence detection threshold choices (i.e., how we decide which fluctuations in incidence are actionable) imply some judgment about the relative cost of true positives (timely resurgence detections) versus false alarms [12]. Incorporating explicit cost structures could mean that delays in detecting resurgence are acceptable. We consider this the next investigative step in our aim to probe the limits of real-time performance.

\section{Bibliography}

1. Cauchemez S, Boëlle P-Y, Thomas G, Valleron A-J. Estimating in real time the efficacy of measures to control emerging communicable diseases. Am J Epidemiol. 2006;164: 591-597. doi:10.1093/aje/kwj274

2. Cori A, Ferguson NM, Fraser C, Cauchemez S. A new framework and software to estimate time-varying reproduction numbers during epidemics. Am J Epidemiol. 2013;178: 1505-1512. doi:10.1093/aje/kwt133

3. The R value and growth rate - GOV.UK [Internet]. [cited 1 Jul 2021]. Available: https://www.gov.uk/guidance/the-r-value-and-growth-rate

4. Li Y, Campbell H, Kulkarni D, Harpur A, Nundy M, Wang X, et al. The temporal association of introducing and lifting non-pharmaceutical interventions with the timevarying reproduction number $(R)$ of SARS-CoV-2: a modelling study across 131 countries. Lancet Infect Dis. 2021;21: 193-202. doi:10.1016/S1473-3099(20)30785-4

5. Funk S, Camacho A, Kucharski AJ, Lowe R, Eggo RM, Edmunds WJ. Assessing the performance of real-time epidemic forecasts: A case study of Ebola in the Western Area region of Sierra Leone, 2014-15. PLoS Comput Biol. 2019;15: e1006785. doi:10.1371/journal.pcbi.1006785

6. Sabino EC, Buss LF, Carvalho MPS, Prete CA, Crispim MAE, Fraiji NA, et al. Resurgence of COVID-19 in Manaus, Brazil, despite high seroprevalence. Lancet. 2021;397: 452-455. doi:10.1016/S0140-6736(21)00183-5

7. Monod M, Blenkinsop A, Xi X, Hebert D, Bershan S, Tietze S, et al. Age groups that sustain resurging COVID-19 epidemics in the United States. Science. 2021;371. doi:10.1126/science.abe8372

8. Wallinga J, van Boven M, Lipsitch M. Optimizing infectious disease interventions during an emerging epidemic. Proc Natl Acad Sci USA. 2010;107: 923-928. doi:10.1073/pnas.0908491107

9. Brauner JM, Mindermann S, Sharma M, Johnston D, Salvatier J, Gavenčiak T, et al. Inferring the effectiveness of government interventions against COVID-19. Science. 2021;371. doi:10.1126/science.abd9338 

medRxiv preprint doi: https://doi.org/10.1101/2021.09.08.21263270; this version posted November $8,2021$. The copyright holder for this
preprint (which was not certified by peer review) is the author/funder, who has granted medRxiv a license to display the preprint in It is made available under a CC-BY-NC-ND 4.0 International license .

10. Parag KV, Donnelly CA. Adaptive estimation for epidemic renewal and phylogenetic skyline models. Syst Biol. 2020;69: 1163-1179. doi:10.1093/sysbio/syaa035

11. Dehning J, Zierenberg J, Spitzner FP, Wibral M, Neto JP, Wilczek M, et al. Inferring change points in the spread of COVID-19 reveals the effectiveness of interventions. Science. 2020;369. doi:10.1126/science.abb9789

12. Johnson P, Moriarty J, Peskir G. Detecting changes in real-time data: a user's guide to optimal detection. Philos Trans A, Math Phys Eng Sci. 2017;375. doi:10.1098/rsta.2016.0298

13. Abbott S, Hellewell J, Thompson RN, Sherratt K, Gibbs HP, Bosse NI, et al. Estimating the time-varying reproduction number of SARS-CoV-2 using national and subnational case counts. Wellcome Open Res. 2020;5: 112.

doi:10.12688/wellcomeopenres.16006.2

14. Gostic KM, McGough L, Baskerville EB, Abbott S, Joshi K, Tedijanto C, et al. Practical considerations for measuring the effective reproductive number, Rt. PLoS Comput Biol. 2020;16: e1008409. doi:10.1371/journal.pcbi.1008409

15. Parag KV. Improved estimation of time-varying reproduction numbers at low case incidence and between epidemic waves. PLoS Comput Biol. 2021;17: e1009347. doi: 10.1371/journal.pcbi.1009347

16. Riley S, Ainslie KEC, Eales O, Walters CE, Wang H, Atchison C, et al. Resurgence of SARS-CoV-2: Detection by community viral surveillance. Science. 2021;372: 990-995. doi:10.1126/science.abf0874

17. du Plessis L, McCrone JT, Zarebski AE, Hill V, Ruis C, Gutierrez B, et al. Establishment and lineage dynamics of the SARS-CoV-2 epidemic in the UK. Science. 2021;371: 708-712. doi:10.1126/science.abf2946

18. Hay JA, Kennedy-Shaffer L, Kanjilal S, Lennon NJ, Gabriel SB, Lipsitch M, et al. Estimating epidemiologic dynamics from cross-sectional viral load distributions. Science. 2021; doi:10.1126/science.abh0635

19. Casella F. Can the COVID-19 Epidemic Be Controlled on the Basis of Daily Test Reports? IEEE Control Syst Lett. 2021;5: 1079-1084.

doi:10.1109/LCSYS.2020.3009912

20. Holmdahl I, Buckee C. Wrong but Useful - What Covid-19 Epidemiologic Models Can and Cannot Tell Us. N Engl J Med. 2020;383: 303-305. doi:10.1056/NEJMp2016822

21. Fraser C, Riley S, Anderson RM, Ferguson NM. Factors that make an infectious disease outbreak controllable. Proc Natl Acad Sci USA. 2004;101: 6146-6151. doi:10.1073/pnas.0307506101

22. Drake JM. Limits to forecasting precision for outbreaks of directly transmitted diseases. PLoS Med. 2006;3: e3. doi:10.1371/journal.pmed.0030003 

medRxiv preprint doi: https://doi.org/10.1101/2021.09.08.21263270; this version posted November $8,2021$. The copyright holder for this
preprint (which was not certified by peer review) is the author/funder, who has granted medRxiv a license to display the preprint in It is made available under a CC-BY-NC-ND 4.0 International license .

23. Kahn R, Peak CM, Fernández-Gracia J, Hill A, Jambai A, Ganda L, et al. Incubation periods impact the spatial predictability of cholera and Ebola outbreaks in Sierra Leone. Proc Natl Acad Sci USA. 2020;117: 5067-5073. doi:10.1073/pnas.1913052117

24. Parag KV. Sub-spreading events limit the reliable elimination of heterogeneous epidemics. J R Soc Interface. 2021;18: 20210444. doi:10.1098/rsif.2021.0444

25. Scarpino S, Petri G. On the predictability of infectious disease outbreaks. Nat Comms. 2019;10.

26. Mercer GN, Glass K, Becker NG. Effective reproduction numbers are commonly overestimated early in a disease outbreak. Stat Med. 2011;30: 984-994. doi:10.1002/sim.4174

27. Britton T, Scalia Tomba G. Estimation in emerging epidemics: biases and remedies. J R Soc Interface. 2019;16: 20180670. doi:10.1098/rsif.2018.0670

28. Parag KV, Cowling BJ, Donnelly CA. Deciphering early-warning signals of the elimination and resurgence potential of SARS-CoV-2 from limited data at multiple scales. medRxiv. 2020; doi:10.1101/2020.11.23.20236968

29. Sarrka S. Bayesian Filtering and Smoothing. Cambridge, UK: Cambridge University Press; 2013.

30. Overview of Syndromic Surveillance What is Syndromic Surveillance? [Internet]. [cited 19 Aug 2021]. Available: https://www.cdc.gov/mmwr/preview/mmwrhtml/su5301a3.htm

31. Syndromic surveillance: systems and analyses - GOV.UK [Internet]. [cited 19 Aug 2021]. Available: https://www.gov.uk/government/collections/syndromic-surveillancesystems-and-analyses

32. Daughton CG. Wastewater surveillance for population-wide Covid-19: The present and future. Sci Total Environ. 2020;736: 139631. doi:10.1016/j.scitotenv.2020.139631

33. Lipsitch M, Finelli L, Heffernan RT, Leung GM, Redd SC, 2009 H1n1 Surveillance Group. Improving the evidence base for decision making during a pandemic: the example of 2009 influenza A/H1N1. Biosecur Bioterror. 2011;9: 89-115. doi:10.1089/bsp.2011.0007

34. Wallinga J, Teunis P. Different epidemic curves for severe acute respiratory syndrome reveal similar impacts of control measures. Am J Epidemiol. 2004;160: 509-516. doi:10.1093/aje/kwh255

35. Pei S, Kandula S, Shaman J. Differential effects of intervention timing on COVID-19 spread in the United States. Sci Adv. 2020;6. doi:10.1126/sciadv.abd6370

36. Morris DH, Rossine FW, Plotkin JB, Levin SA. Optimal, near-optimal, and robust epidemic control. Commun Phys. 2021;4: 78. doi:10.1038/s42005-021-00570-y

37. Fraser $\mathrm{C}$. Estimating individual and household reproduction numbers in an emerging epidemic. PLoS One. 2007;2: e758. doi:10.1371/journal.pone.0000758 

medRxiv preprint doi: https://doi.org/10.1101/2021.09.08.21263270; this version posted November $8,2021$. The copyright holder for this
preprint (which was not certified by peer review) is the author/funder, who has granted medRxiv a license to display the preprint in It is made available under a CC-BY-NC-ND 4.0 International license .

38. Wallinga J, Lipsitch M. How generation intervals shape the relationship between growth rates and reproductive numbers. Proc R Soc B. 2007;274: 599-604.

39. Parag KV, Donnelly CA. Using information theory to optimise epidemic models for realtime prediction and estimation. PLoS Comput Biol. 2020;16: e1007990. doi:10.1371/journal.pcbi.1007990

40. Anderson R, Donnelly C, Hollingsworth D, Keeling M, Vegvari C, Bagalley R et al. Reproduction number $(R)$ and growth rate $(r)$ of the COVID-19 epidemic in the UK: methods of estimation, data sources, causes of heterogeneity, and use as a guide in policy formulation. Tech. rep., The Royal Society; n. https://royalsociety.org//media/policy/ projects/set-c/set-covid-19-R-estimates.pdf

41. Grunwald P. The Minimum Description Length Principle. The MIT Press; 2007.

42. Lehmann EL, Casella G. Theory of point estimation. New York: Springer-Verlag; 1998. doi:10.1007/b98854

43. Guo D, Shamai S, Verdu S. Mutual information and conditional mean estimation in poisson channels. IEEE Trans Inform Theory. 2008;54: 1837-1849. doi:10.1109/TIT.2008.920206

44. Snyder D, Miller M. Random Point Processes in Time and Space. 2nd ed. SpringerVerlag; 1991.

45. Van Kerkhove MD, Bento AI, Mills HL, Ferguson NM, Donnelly CA. A review of epidemiological parameters from Ebola outbreaks to inform early public health decision-making. Sci Data. 2015;2: 150019. doi:10.1038/sdata.2015.19

46. Ferguson N, Laydon D, Nedjati-Gilani G, Imai N, Ainslie K, Baguelin M, et al. Impact of non-pharmaceutical interventions (NPIs) to reduce COVID- 19 mortality and healthcare demand. Imperial College London; 2020; https://wwwimperialacuk/media/imperialcollege/medicine/sph/ide/gida-fellowships/Imperial-College-COVID19-NPI-modelling16-03-2020pdf.

47. Cevik M, Marcus JL, Buckee $\mathrm{C}$, Smith TC. SARS-CoV-2 transmission dynamics should inform policy. Clin Infect Dis. 2020; doi:10.1093/cid/ciaa1442

48. Bialek W, Setayeshgar S. Physical limits to biochemical signaling. Proc Natl Acad Sci USA. 2005;102: 10040-10045. doi:10.1073/pnas.0504321102

49. Parag KV, Vinnicombe G. Point process analysis of noise in early invertebrate vision. PLoS Comput Biol. 2017;13: e1005687. doi:10.1371/journal.pcbi.1005687

50. Lestas I, Vinnicombe G, Paulsson J. Fundamental Limits on the Supression of Molecular Fluctuations. Nature. 2010;467: 174-8.

51. Polonsky J, Baidjoe A, Kamvar Z, Others. Outbreak analytics: a developing data science for informing the response to emerging pathogens. Phil Trans $\mathrm{R}$ Soc $\mathrm{B}$. 2019;374: 20180276. 
medRxiv preprint doi: https://doi.org/10.1101/2021.09.08.21263270; this version posted November 8, 2021. The copyright holder for this preprint (which was not certified by peer review) is the author/funder, who has granted medRxiv a license to display the preprint in It is made available under a CC-BY-NC-ND 4.0 International license .

52. Goldstein E, Dushoff J, Ma J, Plotkin JB, Earn DJD, Lipsitch M. Reconstructing influenza incidence by deconvolution of daily mortality time series. Proc Natl Acad Sci USA. 2009;106: 21825-21829. doi:10.1073/pnas.0902958106

53. Baker MG, Wilson N, Blakely T. Elimination could be the optimal response strategy for covid-19 and other emerging pandemic diseases. BMJ. 2020;371: m4907. doi:10.1136/bmj.m4907

54. Pellis L, Scarabel F, Stage HB, Overton CE, Chappell LHK, Fearon E, et al. Challenges in control of COVID-19: short doubling time and long delay to effect of interventions. Philos Trans R Soc Lond B, Biol Sci. 2021;376: 20200264. doi:10.1098/rstb.2020.0264

55. Parag KV, Thompson RN, Donnelly CA. Are epidemic growth rates more informative than reproduction numbers? medRxiv. 2021; doi:10.1101/2021.04.15.21255565

56. Watts DJ, Muhamad R, Medina DC, Dodds PS. Multiscale, resurgent epidemics in a hierarchical metapopulation model. Proc Natl Acad Sci USA. 2005;102: 11157-11162. doi:10.1073/pnas.0501226102

57. Koyama S, Horie T, Shinomoto S. Estimating the time-varying reproduction number of COVID-19 with a state-space method. PLoS Comput Biol. 2021;17: e1008679. doi:10.1371/journal.pcbi.1008679

58. Liu Q-H, Ajelli M, Aleta A, Merler S, Moreno Y, Vespignani A. Measurability of the epidemic reproduction number in data-driven contact networks. Proc Natl Acad Sci USA. 2018;115: 12680-12685. doi:10.1073/pnas.1811115115

59. Champredon D, Dushoff J, Earn DJD. Equivalence of the Erlang-Distributed SEIR Epidemic Model and the Renewal Equation. SIAM J Appl Math. 2018;78: 3258-3278. doi:10.1137/18M1186411

60. Drake JM, Brett TS, Chen S, Epureanu BI, Ferrari MJ, Marty É, et al. The statistics of epidemic transitions. PLoS Comput Biol. 2019;15: e1006917.

doi:10.1371/journal.pcbi.1006917

\section{Funding}

KVP and CAD acknowledge funding from the MRC Centre for Global Infectious Disease Analysis (reference MR/R015600/1), jointly funded by the UK Medical Research Council (MRC) and the UK Foreign, Commonwealth \& Development Office (FCDO), under the MRC/FCDO Concordat agreement and is also part of the EDCTP2 programme supported by the European Union. CAD thanks the UK National Institute for Health Research Health Protection Research Unit (NIHR HPRU) in Emerging and Zoonotic Infections in partnership 
medRxiv preprint doi: https://doi.org/10.1101/2021.09.08.21263270; this version posted November 8, 2021. The copyright holder for this preprint (which was not certified by peer review) is the author/funder, who has granted medRxiv a license to display the preprint in It is made available under a CC-BY-NC-ND 4.0 International license.

with Public Health England (PHE) for funding (grant HPRU200907). The funders had no role in study design, data collection and analysis, decision to publish, or manuscript preparation. 